\title{
EVALUATION OF A HIGH PERFORMANCE LIQUID CHROMOLOGRAPHY (HPLC) MEHTOD FOR AMINO ACID ANALYSIS IN FEED WITH PRE- COLUMN DERIVATIZATION AND FLUORESCENCE DETECTION
}

\author{
A. B. M. Khaleduzzaman ${ }^{1}$, Z. H. Khandaker ${ }^{2}$, M. S. H. Khan ${ }^{3}$, L. A. Banu ${ }^{4}$ and \\ M. K. A. Khan ${ }^{4}$
}

\begin{abstract}
An experiment was conducted to determine the amino acids content in wheat sample which is often used as internal check in animal feed analysis by pre-column derivatization method using ortho-phthaldialdehyde (OPA) and betamercaptoethanol followed by high-performance liquid chromatography (HPLC). Fluorescence detection was used for the assay of OPA derivatives of amino acids with the detection wavelength set at Ex $340 \mathrm{~nm}$ and Em $455 \mathrm{~nm}$. Ortho-phthaldialdehyde reagent itself does not fluorescence and hence produces no peak on the chromatogram and also produces a very low level of background noise. From standard amino acid mixture fourteen amino acids (Asp, Glu, Ser, Gly, Thr, Arg, Ala, Tyr, Met, Val, Phe, Ile, Leu, and Lys) were separated in 55 min with fine resolution. Good reproducibility and accuracy of the method were demonstrated by the determination of amino acids in wheat sample. The precision for the retention time of amino acids $(n=10$ injections over 3 days $)$ between the days showed average standard deviation (SD) of 0.43 and coefficient of variation (CV) of $3.32 \%$. The average $\mathrm{SD}$ and $\mathrm{CV}$ of peak area repeatability over $\mathrm{n}=10$ injections were 0.72 and $14.93 \%$ also indicated the higher sensitivity of the method. The results of the amino acids in wheat samples suggested that the method can be potentially applied for the determination of amino acids in wheat as well as other cereal feeds used in animal diets.
\end{abstract}

Key words : Amino acids, Ortho-phthaldialdehyde, Wheat, Pre-column derivatization, HPLC, Fluorescence detection

\section{Introduction}

Amino acids are basic elements of protein and play an important role in both animal and human nutrition. The determination of amino acids has become very important to those interested in protein studies. High performance liquid chromatography (HPLC) is now the most widely used technique for such determinations. Two types of derivatization methods such as post-column and pre-column are being used in HPLC system. The former was characterized (Spackman et al., 1958) by an ion-exchange separation technique and generally derivatized with ninhydrin. Since it was developed, this method has been used for

\footnotetext{
${ }^{1}$ Corresponding author, Ph. D student, Department of Animal Nutrition, Bangladesh Agricultural University, Mymensingh, 2202, Bangladesh. Email: abmkhaled@yahoo.com

${ }^{2}$ Department of Animal Nutrition, Bangladesh Agricultural University, Mymensingh, 2202, Bangladesh

${ }^{3}$ Pacific Pharmaceuticals Ltd. Kanchpur, Narayangonj, Bangladesh

${ }^{4}$ Animal Nutrition Section, Department of Livestock Services, Farmgate, Dhaka-1215, Bangladesh
} 
Bang. J. Anim. Sci. 2008, 37(2)

the determination of amino acid in a wide variety of samples and has become a classical method because of its accuracy, reproducibility and automation. However, some disadvantages such as low sensitivity, high instrument expense make this post-column derivatization unsuitable in many countries. Since the 1970s, reversed-phase high performance liquid chromatography (RP-HPLC) has been used for the separation of precolumn derivatized amino acids. Many pre-column derivatization methods (Linroth et al., 1979; Einarsson et al., 1983 and Bidlingmeyer et al., 1984) for amino acid determinations faced interference from excess of reagent which often has similar absorbance or fluorescence emission properties. So, extra steps such as exertion of vacuum or extraction had to be adapted to remove the excess of reagent. Roth (1972) used reversed phase and pre-column derivatization with ortho-phthaldialdehyde (OPA). Now a day, pre-column derivatization with OPA has found as an alternative and more sensitive method to the ninhydrin detection system. Wheat sample is often used as internal check for the quality control of laboratory analysis where amino acid content in animal feed is determined. Therefore, the present study was undertaken to determine the amino acid contents in wheat sample (check sample) by pre-column derivatization with ortho-phthaldialdehyde (OPA) followed by fluorescence detection in high-performance liquid chromatography (HPLC).

\section{Materials and Methods}

\section{Chromatography system}

The amino acid analysis was performed in a KNAUER high pressure binary gradient system, consisting of 2 HPLC pumps (Type 64) equipped with micro-pump head, Rheodyne manual injector, system controller (Software: KNAUER, Eurochrom 2000, Version 1.57 for system control, data acquisition and analysis), dynamic mixing chamber, a high temperature oven with temperature control unit, and coupling with fluorescence detector fixed for OPA. A Vertex Column (Lichrospher $100 \mathrm{RP}-18$ endcapped $5 \mu \mathrm{m}$ ) 250 x $4 \mathrm{~mm}$ ID from KNAUER was used. A guard column cartridge was used to protect the column.

\section{Chemicals and reagents}

Ortho-phthaldialdehyde and all other reagents were of analytical grade from Merck, Germany. Methanol and acetonitrile were HPLC grade from Merck, Germany. Deionized water was generated using an ultra pure water purification system. Hydrochloric acid, phenol, mono and disodium hydrogen phosphate were extra pure from Merck (Germany). Amino acids standard solution was from Sigma, USA. Borate buffer was supplied from Chrom, Germany.

\section{N-phenol HCl solution}

One or two crystals of phenol were added to $12 \mathrm{~N} \mathrm{HCl}$ solution.

\section{Mobile phase}

Eluent-A : 93\% $12.5 \mathrm{mM}$ phosphate buffer and 7\% acetonitrile (pH 6.5) 
Eluent-B : $100 \%$ methanol.

Prepared freshly and was filtered through $0.22 \mu \mathrm{m}$ membrane filter (Millipore).

\section{Derivatizing reagents}

Reaction mixture-1 : $10 \mathrm{ml}$ of $100 \mathrm{mM}$ boric acid buffer solution (pH 9.1) containing $10 \mu 1$ of $\beta$-mercaptoethanol. Reaction mixture was prepared freshly everyday.

Reaction mixture-2 : $10 \mathrm{ml}$ of $100 \mathrm{mM}$ boric acid buffer solution (pH 9.1), add $3 \mathrm{ml}$ of OPA $(10 \mathrm{mg} / 3 \mathrm{ml}$ ethanol). Reaction mixture was prepared freshly everyday.

\section{Preparation of calibration standard and internal standard}

Calibration standard was $2.5 \mathrm{mM}$ mixture of 17 amino acids with the exception in case of cystine $(1.25 \mathrm{mM})$. The amino acids in the standard mixture were Asp, Glu, Ser, Thr, Tyr, Met, Val, Ala, Phe, Pro, Leu, Arg, Lys, Ile, Gly, His and Try. In order to prepare $2.5 \mathrm{mM}$ internal standard stock solution, $6.45 \mathrm{mg}$ of alpha amino butyric acid (AABA) was added to $25 \mathrm{ml}$ of $0.1 \mathrm{M} \mathrm{HCl}$ solutions. Internal standard stock solution was stored at $-20^{\circ} \mathrm{C}$. Five hundred micro liters $(500 \mu \mathrm{l})$ of amino acid standard mixture $(2.5 \mathrm{mM})$ was added to $500 \mu 1$ of internal standard stock solution $(2.5 \mathrm{mM})$ to prepare calibration standard with internal standard.

\section{Sample preparation and hydrolysis}

The well mixed wheat sample was finely ground to pass through $0.25 \mathrm{~mm}$ sieve and divided into 10 equal portions. Seven hundred milligrams of powdered samples (equivalent to around $10 \mathrm{mg}$ nitrogen content) were taken in each digestion tubes separately and were hydrolysed using liquid-phase hydrolysis procedure suggested by AOAC International (2000). Methionine and cystine might undergo oxidation during acid hydrolysis. To prevent that oxidation, the wheat sample was subjected to oxidation with performic acid. The excess reagent was removed by using vacuum evaporator. Equal volumes of $12 \mathrm{~N}$-phenol $\mathrm{HCl}$ solution and $2.5 \mathrm{mM}$ internal standard stock solution mixed together where resultant strength of $\mathrm{HCl}$ solution became $6 \mathrm{~N}$ and the concentration of internal standard was $1.25 \mathrm{mM}$. Twenty micro liters of $6 \mathrm{~N}$-phenol $\mathrm{HCl}$ acid solution containing internal standard of $1.25 \mathrm{mM} \mathrm{AABA}$ was added to performic acid treated wheat sample and hydrolysed for $24 \mathrm{~h}$ at $115^{\circ} \mathrm{C}$. After cooling, $500 \mu \mathrm{l}$ of protein hydrolysate was taken in an eppendorf tube and centrifuged at $3000 \mathrm{rpm}$ for 10 minutes. The clear supernatant was collected and filtered through a $0.45 \mu \mathrm{m}$ filter (Millipore) which was considered as hydrolysate.

\section{Derivatization with OPA}

Ten micro liters of calibration standard solution was added to $175 \mu \mathrm{L}$ of reaction mixture-1, votexed and then added to $175 \mu \mathrm{L}$ of reaction mixture-2. Twenty micro liters of derivatized standard sample was injected within 2 minutes of derivatization in the HPLC system. In case of sample $10 \mu \mathrm{L}$ of hydrolysate was dried with nitrogen flushing and was added $185 \mu \mathrm{L}$ of 
Bang. J. Anim. Sci. 2008, 37(2)

reaction mixture- 1 and vortexed. Then $175 \mu \mathrm{L}$ of reaction mixture- 2 was added and vortexed again. Twenty micro liters of derivatized sample was injected in the HPLC system.

\section{Chromatographic condition}

System was operated under the gradient condition made from Eluent A $(93 \% 12.5 \mathrm{mM}$ phosphate buffer and $7 \%$ acetonitrile) to Eluent B (100\% methanol). The detection was done using fluorescence detector at excitation wavelength (Ex) $340 \mathrm{~nm}$ and emission wavelength (Em) $455 \mathrm{~nm}$. The eluent flow rate was $0.9 \mathrm{ml} /$ minute and the column was maintained at $40^{\circ}$ C. The gradientprogram used for chromatographic separation of amino acids is shown in Table 1. Derivatized amino acid standard and sample hydrolysates were injected accordingly and the standard deviation (SD) and coefficient of variation (CV) of retention time and peak area of each amino acid were calculated.

Table 1. Gradient program for OPA amino acid analysis

\begin{tabular}{|c|c|c|}
\hline Time (min) & Eluent A (\%) & Eluent B (\%) \\
\hline 0 & 100 & 0 \\
26 & 81 & 19 \\
50 & 35 & 65 \\
55 & 35 & 65 \\
60 & 100 & 0 \\
65 & 100 & 0 \\
\hline
\end{tabular}

\section{Calculation of amino acids}

$$
\text { Response factor }\left(\mathrm{R}_{\mathrm{f}}\right)=\frac{\text { Weight of standard AA/area of standard AA }}{\text { Weight of IS/Area of IS }}
$$

Amino acid content $(\%)=\frac{\mathrm{R}_{\mathrm{f}} \times \text { Area of AA in sample }}{\text { Area of IS peak in sample }} \times \frac{\text { Weight of IS }}{\text { Sample weight }} \times 100$

Where, $\mathrm{AA}=$ Amino acid

IS $=$ Internal standard

\section{Results and Discussion}

\section{Separation of amino acids}

Chromatogram of standard amino acid mixture is shown in Fig. 1. Standard amino acid mixture from Sigma contained 17 amino acids but as viewed in the chromatogram (Fig. 1) 14 amino acids (Asp, Glu, Ser, Gly, Thr, Arg, Ala, Tyr, Met, Val, Phe, Ile, Leu, and Lys) were separated in $55 \mathrm{~min}$ with fine resolution. The amino acids were identified according to their characteristic retention time as revealed when injected individually following the same 
procedure. The peak of tryptophan, cystine and proline did not appear and the peak of histidine as broaden and remained out of integration. OPA does not react with secondary amines such as praline. However, a negligible peak beyond the detection limit was observed whose position coincide with that of proline. Ortho-phthaldialdehyde (O-phthalaldehyde) reagent itself was not fluorescent and hence produced no peak on the chromatogram and generated a very low level of background noise (Fig. 1) as compared to other fluorescence reagents (FMOC). The aspartic acid eluted first having the retention time $6.39 \mathrm{~min}$. and observed no interference with reagent. The AABA (internal standard) peak eluted at 42.89 min. and did not overlap with other amino acids. Lysine was the last eluted amino acid and the retention time was $54.56 \mathrm{~min}$.

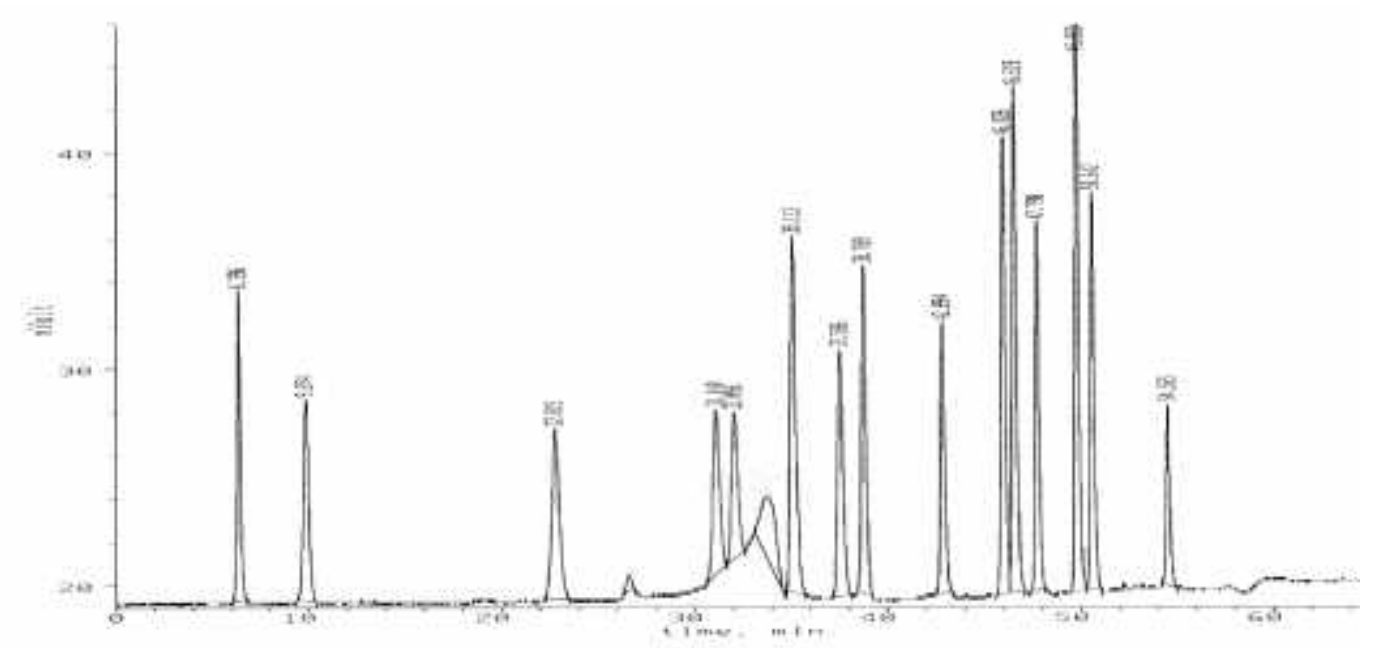

Fig. 1. A typical chromatogram of OPA derivatives with amino acid standard containing 14 amino acids. Derivatization procedure: (1) $175 \mu \mathrm{l}$ of reaction mixture-1 (10 $\mathrm{ml}$ of $100 \mathrm{mM}$ boric acid buffer solution pH-9.1 containing $10 \mu \mathrm{l}$ of beta-mercaptoethanol) added to $10 \mu \mathrm{l}$ of amino acid standard and vortex; (2) add $175 \mu \mathrm{l}$ of reaction mixture-2 $(10 \mathrm{ml}$ of $100 \mathrm{mM}$ boric acid buffer solution $\mathrm{pH}-9.1$, add $3 \mathrm{ml}$ of OPA 10 $\mathrm{mg} / 3 \mathrm{ml}$ in ethanol) and vortex and (3) Inject $20 \mu \mathrm{l}$ within 2 minutes.

\section{Determination of amino acids in wheat samples}

The chromatographic profile of OPA-derivatized amino acids in wheat sample is shown in Fig. 2. Fourteen amino acids (Asp, Glu, Ser, Gly, Thr, Arg, Ala, Tyr, Met, Val, Phe, Ile, Leu, and Lys) in wheat sample were separated with fine resolution and negligible background noise. Identification of each amino acid peak was ascertained by matching its retention time with the respective one obtained in the chromatogram of standard amino acid mixture. During acid hydrolysis glutamine and asparagine inevitably converted into glutamic acid and aspartic acid respectively and according were shown as Glx (Glu + Gln) and Asx (Asp + Asn) in the text and Table 3. As observed in chromatogram (Fig. 1) of standard amino acid mixture, the peak of Trp, Pro, Cys and His were also absent in the chromatogram (Fig. 2) of wheat sample. Tryptophan was destroyed in acid hydrolysis and proline as a secondary amine did not produce adduct with OPA and mercaptoethanol. Hence, for these two amino 
Bang. J. Anim. Sci. 2008, 37(2)

acids, no peak could be expected. Generally, methionine undergoes oxidation during acid hydrolysis. However, prior treatment of wheat sample with performic acid made it possible to obtain a well separated and reasonable peak for methionine. The average standard deviation (SD) and coefficient of variation $(\mathrm{CV})$ of retention time and peak area of amino acid standard ( $\mathrm{n}=10$ injections) as well as wheat sample ( $\mathrm{n}=10$ injections) over 3 days are shown in Table 2 and Table 3 respectively. The SD of retention time of different amino acids in standard varied from 0.32 to 0.65 and the average value was found as 0.42 (Table 2). In the same way, the CV ranged from $0.7 \%$ to $8.7 \%$ showing the average value of $2.32 \%$. Thippeswamy et al. (2007) indicated the precision of retention time of $\beta$-N-oxalyl-L- $\alpha$, $\beta$ diaminopropionic acid ( $\beta$-ODAP) only over 10 runs and showed a SD of 0.078 and CV of $0.68 \%$ within and between days.

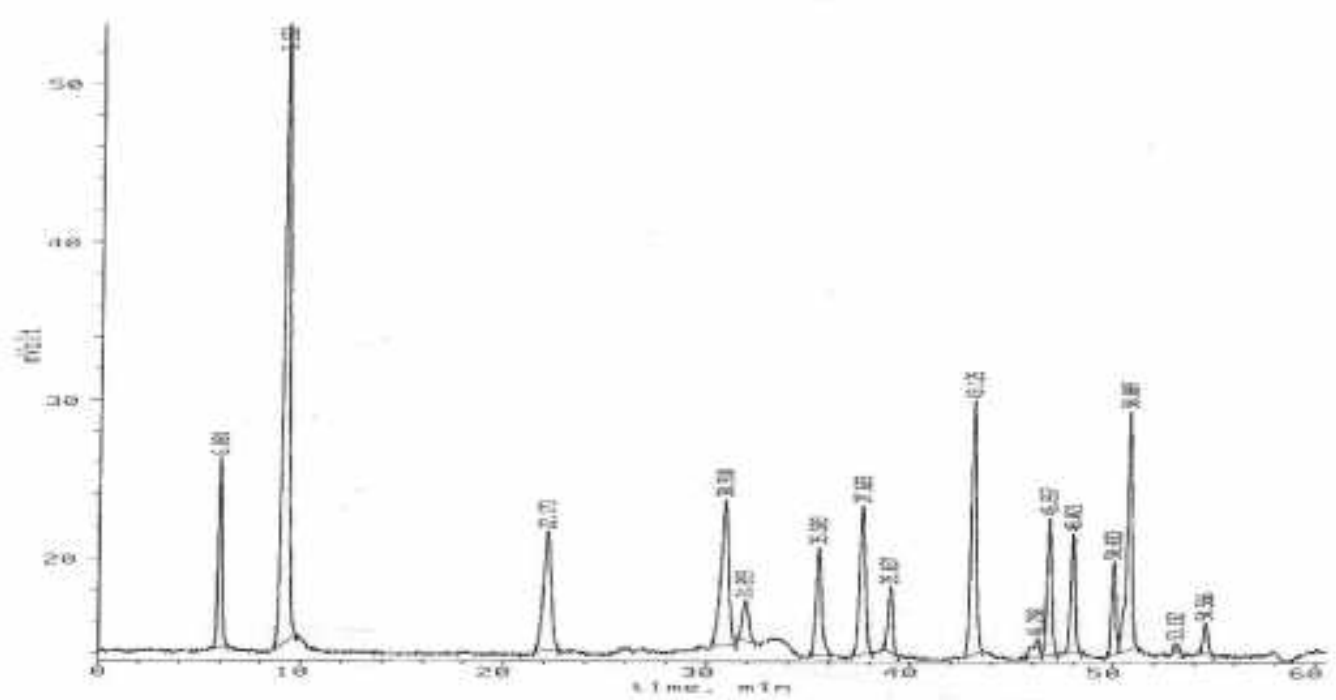

Fig. 2. A chromatogram of OPA derivatives with wheat hydrolysate containing 14 amino acids. Derivatization procedure: (1) $175 \mu \mathrm{l}$ of reaction mixture-1 $(10 \mathrm{ml}$ of $100 \mathrm{mM}$ boric acid buffer solution $\mathrm{pH}-9.1$ containing $10 \mu \mathrm{l}$ of beta-mercaptoethanol) added to $10 \mu \mathrm{l}$ of wheat hydrolysate and vortex; (2) add 175 $\mu \mathrm{l}$ of reaction mixture-2 $(10 \mathrm{ml}$ of $100 \mathrm{mM}$ boric acid buffer solution $\mathrm{pH}-9.1$, add $3 \mathrm{ml}$ of OPA 10 $\mathrm{mg} / 3 \mathrm{ml}$ in ethanol) and vortex and (3) Inject $20 \mu \mathrm{l}$ within 2 minutes.

The SD and CV of retention time in the present investigation were much higher than those of reported values by Thippeswamy et al. (2007). However, he worked on a single compound but in the present study fourteen amino acids were taken into consideration. Moreover, the lowest value of SD and CV were 0.32 and $0.7 \%$ respectively which were reasonably close to the reported values. Similarly, the average SD and CV of retention time in wheat samples were found 0.43 and $3.32 \%$ respectively and the values were much higher than the reported values. The average SD and CV of peak area repeatability in amino acid standard over $\mathrm{n}=$ 10 injections were 0.75 and $13.37 \%$ and in wheat samples were 0.72 and $14.93 \%$ respectively. The values of the present experiment were relatively higher than those of Thippeswamy et al. (2007) where he had shown that the CV was $2.3 \%$ when ten injections 
were made within a day and CV varied from $2.3-4.4 \%$ between the days $(\mathrm{n}=10$ injections over 7 days).

Table 2. Standard deviation (SD) and coefficient of variation (CV) of retention time and peak area of the amino acid standards

\begin{tabular}{|l|c|c|c|c|c|c|}
\hline \multirow{2}{*}{ Amino acids } & \multicolumn{3}{|c|}{ Retention time* } & \multicolumn{3}{c|}{ Peak area* } \\
\cline { 2 - 7 } & Time & SD & CV\% & Area & SD & CV\% \\
\hline Asn & 6.39 & 0.35 & 8.7 & 2.62 & 1.11 & 10.2 \\
Gln & 9.87 & 0.32 & 3.8 & 2.52 & 1.62 & 11.0 \\
Ser & 22.81 & 0.51 & 2.2 & 3.10 & 1.21 & 12.6 \\
Gly & 31.14 & 0.32 & 3.5 & 2.50 & 1.48 & 13.8 \\
Thr & 32.09 & 0.37 & 1.9 & 2.16 & 0.65 & 16.5 \\
Arg & 35.11 & 0.54 & 3.4 & 5.16 & 0.60 & 15.4 \\
Ala & 37.58 & 0.36 & 1.5 & 3.45 & 0.42 & 10.0 \\
Tyr & 38.78 & 0.52 & 1.2 & 3.93 & 0.40 & 11.0 \\
Met & 46.02 & 0.52 & 1.1 & 5.07 & 0.32 & 12.6 \\
Val & 46.62 & 0.36 & 1.7 & 5.92 & 0.79 & 16.2 \\
Phe & 47.79 & 0.37 & 0.8 & 3.95 & 0.42 & 12.2 \\
Ile & 49.05 & 0.36 & 0.8 & 6.12 & 0.80 & 19.6 \\
Leu & 50.64 & 0.37 & 0.7 & 4.39 & 0.70 & 12.0 \\
Lys & 54.56 & 0.65 & 1.2 & 2.02 & 0.22 & 14.2 \\
\hline Average & \multicolumn{7}{c}{$\mathbf{0 . 3 2}$} \\
\hline
\end{tabular}

$*_{\mathrm{n}}=10$ injections

Table 2. Retention time, peak area and amino acids (\%) of wheat sample derivatized with OPA ( $n=10$ injections over 3 days $)$

\begin{tabular}{|c|c|c|c|c|c|c|c|c|}
\hline \multirow{2}{*}{$\begin{array}{c}\text { Amino } \\
\text { acids }\end{array}$} & \multicolumn{3}{|c|}{ Retention time* } & \multicolumn{3}{|c|}{ Peak area* } & \multirow{2}{*}{$\begin{array}{c}\text { AAs\%* } \\
\text { (Mean value) }\end{array}$} & \multirow{2}{*}{ CV (\%) } \\
\hline & Time & SD & CV\% & Area & SD & $\mathrm{CV} \%$ & & \\
\hline Asx & 6.08 & 0.45 & 8.7 & 2.93 & 0.37 & 11.0 & 0.73 & 11.77 \\
\hline Glx & 9.10 & 0.32 & 3.8 & 15.97 & 1.27 & 9.3 & 3.44 & 15.88 \\
\hline Ser & 22.17 & 0.51 & 2.2 & 4.25 & 0.67 & 6.60 & 0.59 & 9.03 \\
\hline Gly & 30.91 & 0.46 & 5.2 & 5.30 & 1.20 & 14.0 & 0.50 & 11.65 \\
\hline Thr & 31.09 & 0.37 & 3.1 & 1.46 & 0.69 & 17.0 & 0.37 & 12.20 \\
\hline Arg & 35.50 & 0.37 & 4.2 & 3.60 & 0.62 & 19.4 & 0.61 & 13.01 \\
\hline Ala & 37.66 & 0.36 & 1.0 & 4.42 & 0.74 & 16.0 & 0.45 & 23.51 \\
\hline Tyr & 39.03 & 0.52 & 1.2 & 1.71 & 0.63 & 12.0 & 0.39 & 10.65 \\
\hline Met & 46.25 & 0.58 & 1.1 & 0.66 & 0.49 & 18.0 & 0.20 & 21.00 \\
\hline Val & 46.86 & 0.36 & 2.7 & 4.41 & 0.91 & 16.0 & 0.52 & 11.04 \\
\hline Phe & 48.02 & 0.37 & 3.7 & 2.89 & 0.44 & 12.7 & 0.59 & 13.29 \\
\hline Ile & 50.05 & 0.36 & 2.7 & 3.45 & 0.99 & 24.0 & 0.37 & 16.81 \\
\hline Leu & 50.80 & 0.37 & 2.7 & 5.97 & 0.76 & 12.0 & 0.77 & 19.86 \\
\hline Lys & 54.56 & 0.65 & 4.2 & 1.04 & 0.39 & 21.0 & 0.33 & 12.78 \\
\hline Average & & 0.43 & 3.32 & & 0.72 & 14.93 & & 14.46 \\
\hline
\end{tabular}

$*_{\mathrm{n}}=10$ samples 
Bang. J. Anim. Sci. 2008, 37(2)

However, the coefficient of variation for Ile, Lys and Arg were 24\%, 21\% and 19.4\% respectively which are much higher than the calculated average value $(14.93 \%)$. From the analytical point of view, Liu (1994) found largest error in Met content when bovine serum albumin sample was analyzed by HPLC. The amino acids content in wheat sample (hydrolysate) is presented in Table 3. The values for the amino acids such as Asx, Glx, Ser, Gly, Thr, Arg, Ala, Tyr, Met,Val, Phe, Ile, Leu, and Lys were 0.73, 3.44, 0.59, 0.50, 0.37, $0.61,0.45,0.39,0.20,0.52,0.59,0.37,0.77$ and $0.33 \%$ respectively. The result of the present study was compared with the values as shown by Degussa (AminoDat 1.1, 1997), Germany and the values were $0.73,3.66,0.60,0.54,0.38,0.64,0.48,0.39,0.21,0.56,0.61,0.44,0.87$ and $0.38 \%$ respectively which are in line with the present investigation. They followed the same experimental procedure as practiced in the present study.

\section{Conclusion}

The results of amino acids in wheat sample described in this paper demonstrate that the accuracy of the method with OPA pre-column derivatization and fluorescence detection is trustworthy and sensitive enough for the routine amino acid analysis of wheat as well as other cereal feeds used in animal diets.

\section{Acknowledgements}

The research work was done with the cooperation extended by "Poultry Sector Development Project", Department of Livestock Services, Krishi Khamar Sarak, Farmgate, Dhaka- funded by Canadian International Development Agency (CIDA).

\section{Literature Cited}

AOAC. 2000. Official Methods of Analysis. Association of Official Analytical Chemist. 17 $7^{\text {th }}$ Ed., Washington DC, USA.

Bidlingmeyer, B. A., Cohen, S. A. and Tarvin, T. L. 1984. J. Chromatography. 336 : 93-104.

Degussa, 1997. Amino acid values of different Indian Feed ingredients. Personal communication. Degussa, A. G. Frankfurt, Germany

Einarsson, S., Josefsson, B. and Lagerkvist, S. 1983. J. Chromatography. 282 : 609-618.

Linroth, P. and Mopper, K. 1979. Analytical Chemistry. 51: 1667 - 1674.

Liu, H. J. 1994. Determination of amino acids by precolumn derivatization with 6-aminoquinolyl-Nhydroxysuccinimidyl carbonate and high performance liquid chromatography with ultraviolet detection. J. of Chromatography A. $670: 59-66$.

Roth, M. 1972. Analytical Chemistry. $43: 880$ - 882.

Spakman, D. H., Stein, W.H. and Moore, S. 1958. Analytical Chemistry. 30 : 1990-205.

Thippeswamy, R., Martin, A. and Gowda, L. R. 2007. A reverse phase high performance liquid chromatography method for analyzing of neurotoxin beta-N-oxalyl-L-alphabetapdiaminopropanoic acid in legume seeds. Food Chemistry. $101: 1290-1295$. 